\title{
International Journal of Modern Researeh in Electrical and Electronic Engineering
}

Vol. 1, No. 1, 16-28, 2017

http://www.asianonlinejournals.com/index.php/IJMREER

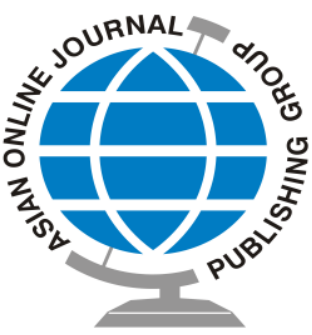

CrossMark

\section{Smart Utilization of Batteries in Grid-Connected PV-Plants}

\begin{tabular}{ll|l|}
\hline Rosario Carbone" (D) & \\
\hline${ }^{1}$ University "Mediterranea" of Reggio Calabria - Italy & \\
\hline
\end{tabular}

\begin{abstract}
Energy storage is undoubtedly a crucial aspect for the optimal managing of modern active distribution systems. In this paper, a smart utilization of batteries within grid-connected PV-plants is introduced and discussed. Batteries are utilized for maximizing the power generation of a PV-field operating under partial shading conditions, also obtaining the conventional energy storage task. In fact, batteries are proposed to be utilized in a distributed framework together with simple boost-type DC-DC converters; by this way, the power generated by a PV-field can be maximized also in presence of significant mismatches among different PV-modules connected in series, attaining some important advantages with respect to both conventional PV-plants with a centralized energy storage system or to conventional distributed Maximum Power Point Tracking (MPPT) systems with no batteries. Experimental and numerical data are presented, analyzed and discussed.
\end{abstract}

Keywords: Energy storage, Batteries, Grid-Connected PV-plants, Distributed MPPTs.

\section{Contents}

1. Introduction.

2. Using Batteries as a "First Order" Passive MPPT

3. Introducing a Boost-Type DC-DC Converter Acting as a "Second Order" Active MPPT ...................................................19

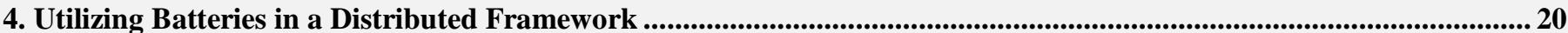

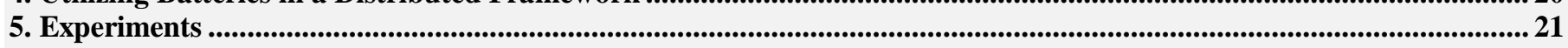

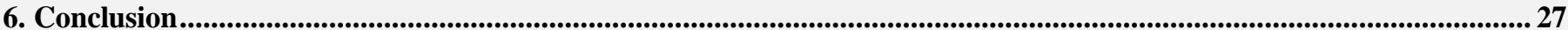

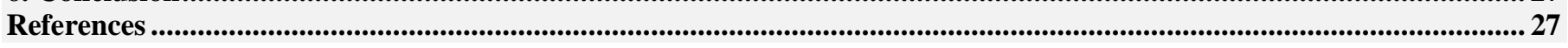

Citation | Rosario Carbone (2017). Smart Utilization of Batteries in Grid-Connected PV-Plants. International Journal of Modern Research in Electrical and Electronic Engineering, 1(1): 16-28.

DOI:

Licensed:

10.20448/journal.526/2017.1.1/526.1.16.28 Crossref

Funding:

This work is licensed under a Creative Commons Attribution 3.0 License $\left(\right.$ (c) EY $_{\text {EY }}$

Competing Interests:

This study received no specific financial support.

Transparency:

The author declares that there are no conflicts of interests regarding the publication of this paper.

History:

The author confirms that the manuscript is an honest, accurate, and transparent account of the study was reported; that no

Ethical:

vital features of the study have been omitted; and that any discrepancies from the study as planned have been explained.

Publisher:

Received: 5 December 2015/ Revised: 27 December 2016/ Accepted: 4 January 2017/ Published: 13 January 2017

This study follows all ethical practices during writing.

Asian Online Journal Publishing Group 


\section{Introduction}

Traditional electrical power systems were essentially based on centralized and fuel consuming power generation plants, where end-users were supplied via unidirectional transmission and distribution grids.

The need for reducing $\mathrm{CO} 2$ emissions are now changing these strongholds and power systems are more and more integrated by "distributed generation" (DG), that is to say small and medium size generator plants managed by endusers (now called "prosumers", to underline that they can be both consumers and producers) and essentially based on renewables.

As a consequence, in order to not compromise reliability and quality of the supply, modern power systems have now to become "smarter", for properly managing power received both from centralized and distributed sources; of course, this could be accomplished by means of sophisticated control and communication technologies but, undoubtedly, also energy-storage systems can have a central role [1-14].

In fact, electricity generated from renewables by distributed plants, unlike to that generated by fuel consuming centralized plants, is highly "intermittent" and this worsens the problem of optimally matching electricity availability with electricity demand of end-users. Without solving this problem, reliability, quality and stability of modern power system are seriously compromised.

A non exhaustive list of further benefits of the energy storage, properly located on modern power systems with DG, could be as follows: it can increase voltage control, frequency control and stability of power systems, it can reduce outages, it can allow the reduction of spinning reserves to meet peak power demands, it can reduce congestion on the transmission and distributions grids, it can release the stored energy when energy is most expensive, it can improve power quality or service reliability for customers with high value processes or critical operations and so on. A lot of recent studies demonstrate the strategic importance and advantages of introducing energy storage systems within modern power systems also for making possible a very high penetration of variable renewable electricity.

Nevertheless, the evaluation of the "net economical performance" of the utilization of a battery energy storage system - by economically comparing its advantages and benefits with its additional costs, its maintenance costs, its charge/discharge inefficiencies and its lifetime - is still hotly debated today so showing to be a complex issue. As an example, in Nicholas, et al. [15] it was concluded that: "it is clear that many details should be considered when evaluating the economic potential of behind-the-meter storage for demand-charge reduction. In addition to considering the weather and load profiles of the site, it is necessary to evaluate the utility rate structure, and determine whether the addition of battery storage can be leveraged to reduce costs enough to justify the upfront capital expenditure and replacement costs. The greatest financial benefit will be derived at certain sizes of PV and battery couplings, requiring optimization or parametric analysis. Further complications result when considering how to dispatch the battery to maximize its benefit, especially because load and weather forecasts are uncertain, and battery lifetime depends on cycling behavior. SAM provides a means to begin evaluating these complex problems". Furthermore, at moment, a large number of energy storage technologies and systems are available and effectively viable; nevertheless, existing storage technologies can be complimented with innovative researches in order to find new, more reliable and cost-effective solutions.

In this contest, the main goal of this paper is that of discussing a "smart way" of conceiving a battery-based energy storage system to be utilized in grid-connected PV-plants as a base for coping with the additional task of implementing a reliable, efficient and affordable distributed MPPT. Differently from the conventional and "centralized" use of batteries, we propose to use batteries in a "distributed framework", by properly coupling them with a certain number of sub-PV-strings and its respective MPPT circuitry. By this way - without additional costs for batteries (that are just "distributed" on the PV-field with respect to its centralized use) - some relevant additional advantages can be attained, all having an immediate and favorable economical impact: i) generation losses caused by mismatches and partial shading are avoided (as in conventional distributed MPPTs without batteries); ii) overvoltages on sensitive components of sub-PV-string circuitries under mismatches are eliminated (with respect to conventional distributed MPPTs without batteries); iii) conversion losses on DC/DC converters are reduced (thanks to the reduction of conduction losses on power switches); iv) conversion efficiency of the centralized inverter is improved (thanks to the stabilization of its DC input voltage and power); v) costs for capacitors of DC/DC converters are avoided; vi) costs for conventional bypass diodes for sub-PV-strings are avoided. In a nutshell, to optimally managing the power generation of a PV-field that can be disturbed by significant mismatches among its PV-modules, in virtue of its power and its solar exposure, the PV-field is partitioned into a certain number of sub-PV-strings, whose series-connected PV-modules are characterized - as much as possible - by a uniform exposure to atmospheric agents. Finally, for each sub-PV-string a properly designed battery pack is introduced; regardless of its capacity, which does not directly/immediately affect the generation properties of the sub-PV-string, its rated voltage as to be matched as best as possible to the sub-PV-string maximum power voltage. By this way, batteries should act as an effective "first order passive MPPT". In order to compensate for both unavoidable errors in finding commercial battery-packs with a rated voltage equal to the theoretical optimal value and for losses on the generated power caused by variations of operating conditions (i.e. the working temperature of PV-cells), each battery pack is connected to its respective sub-PV-string via a simple boost-type DC/DC converter. In practice, DC/DC converters are proposed to be used just to "refine" in an active way the voltage value at the terminals of each Sub-PV-string, starting from the rated voltage of the battery-pack. In this sense, each sub-PV-string DC/DC converter works - de facto - as a "second order active MPPT"; anyhow, it can be operated with very low values of its duty cycle, $\mathrm{k}$, and, as a consequence, minor conversion losses are expected with respect to DC/DC converters operated without the battery presence, thanks to a significant reduction of conduction losses on power switches. After introducing aforementioned batterybased DC/DC converters, sub-PV-strings can be connected in series among them to supply the central PV-string inverter, without encountering well known problems of generation losses that occur in conventional PV-strings without batteries, not even in case of mismatches among series-connected PV-modules [16-22]. Furthermore, no variations occur on the PV-string output voltage (that is also the input DC voltage of the centralized inverter) and no overvoltages on circuit components appear, not even in presence of strong mismatches among PV-modules, as - 
instead - it is in conventional distributed MPPTs without batteries [23-25].

An inclusive Pspice numerical model of the proposed PV-plant architecture, already introduced and fully described in Carbone, et al. [26] is firstly set with the help of measurements on a small-scale simplified lab prototype; then, the Pspice numerical model is utilized to simulate different PV-generator case-studies operating under different working conditions.

\section{Using Batteries as a "First Order" Passive MPPT}

As well known, for a fixed level of the solar irradiance and for a fixed temperature, the power delivered to the network by a conventional grid-connected photovoltaic generator (PG), which qualitative I-V characteristic is depicted in Fig.1(a), depends on the value of the network equivalent impedance as seen from the PG terminals. Moreover, the behavior of the network is normally imposed to be resistive by using a power PWM inverter.

Unfortunately, only one working point on the I-V PG characteristic corresponds to the generation of the maximum available power, MPP (bold-faced circles, in Fig.1(a)) and it can be "caught" only carefully adjusting the value of the network equivalent resistance. Hence, in grid-connected PV-plants maximum power point trackers (MPPTs) are largely used; they belong to the active category and are based on power electronic interfaces (singlestage or double-stage forced commutated PWM inverters), operated according to different algorithms (perturbobserve, incremental conductance and so on). Of course, active MPPTs have high performances; nevertheless, they normally require a complex circuitry.

On the other hand, Fig.1 also shows that, for different solar irradiance (SI) levels, the variation of the MPP directly involves the PG current values, while the PG voltage values remain almost constant.

This means that a battery, in parallel with the PG and the network as shown in Fig.1(b), if properly designed in its rated voltage value, can naturally catch and maintain (within limits imposed by the capacity of the battery) a PG working point very close to the MPP, for any PG solar irradiance level and for any value of the network equivalent resistance [2] in other words, a battery in parallel with the PG - if well designed in its rated voltage - could work as an effective "passive" MPPT.
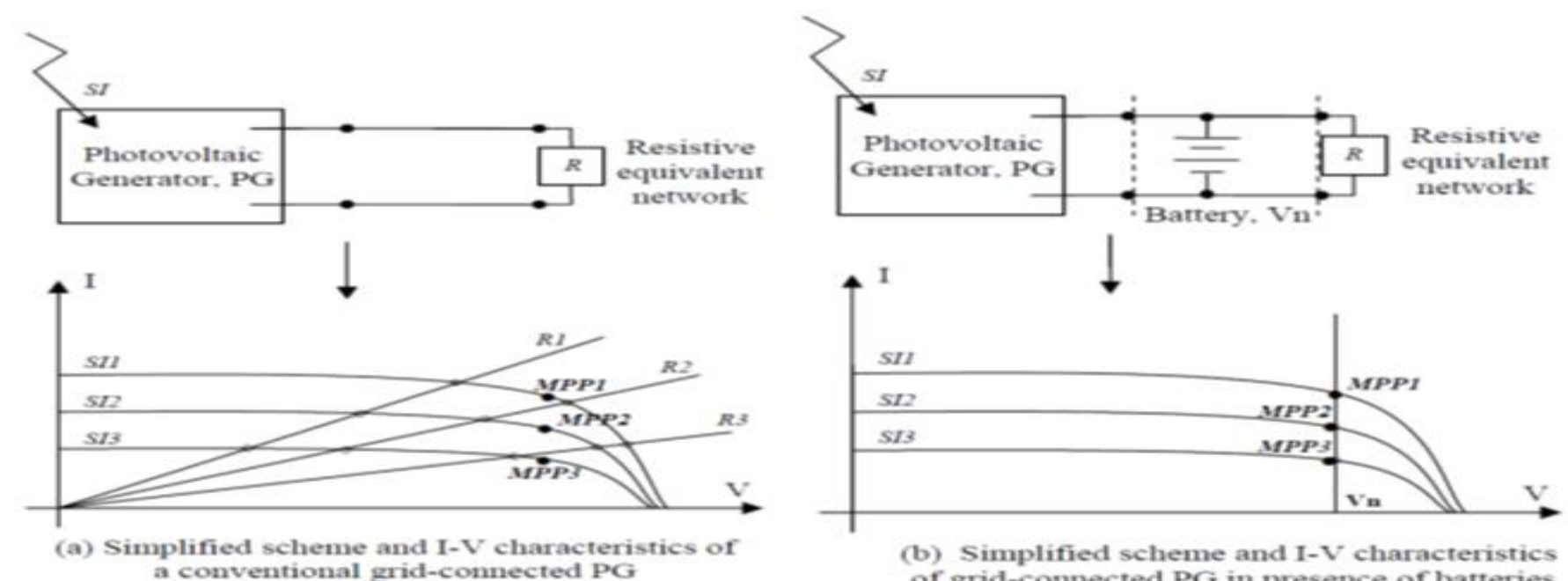

(b) Simplified scheme and I-V characteristics of grid-connected $P G$ in presence of batteries

Fig-1. Working points in grid-connected PV-generators, without (a) and with (b) the use of batteries

With some more detail, it is well known that, under standard conditions (i.e. $1000 \mathrm{~W} / \mathrm{m}^{2}$ of solar irradiance, SI, and $25{ }^{\circ} \mathrm{C}$ of PV-cells temperature, $\mathbf{T c}$ ) the voltage, $\mathbf{V}_{\mathbf{m p}}$, to be put at the terminals of a photovoltaic generator, PG, for the generation of its maximum available power, has a value that is about the $80 \%$ of the open circuit voltage, $\mathbf{V}_{\text {oc }}$, of the PG. Please also note that, as already indicated in Fig.1(a), this $\mathbf{V}_{\mathbf{m p}}$ value shows a small decreasing when the solar irradiance level, SI, decreases (with respect to the standard value of $1000 \mathrm{~W} / \mathrm{m}^{2}$ ). Furthermore, it is also well known that the $\mathbf{V}_{\mathbf{m p}}$ value sensibly decreases if the working temperature, Tc, of PV-cells increases (with respect to the standard value of $25^{\circ} \mathrm{C}$ ) and vice versa.

That said, once a sub-PV-string has been planned as briefly indicated in the introduction and also fully identified (i.e. the number of PV-modules to be connected in series and their operating characteristics are identified) its theoretical maximum power voltage, $\mathbf{V}_{\mathbf{m p}}$, under standard conditions can be easily determined. So, in order to design a good battery-pack to be put in parallel to the sub-PV-string, so obtaining an effective passive MPPT, the most important problem to be solved could seem only that of matching - as best as possible - the rated voltage of the battery-pack, $\mathbf{V}_{\text {batt, }}$, with the aforementioned $\mathbf{V}_{\text {mp }}$ value, within limits of commercial availability of batteries.

Unfortunately, the problem to be solved is a little more complex.

Firstly, variations of both the SI levels and mostly the Tc values impose - anyhow - the inclusion of a DC/DC converter to be interposed between the sub-PV-string and the battery-pack, for compensating for aforementioned variations, by adjusting the voltage value at the terminals of the sub-PV-string, $\mathbf{V}_{\mathbf{p v}}$, starting from the almost constant $\mathbf{V}_{\text {batt }}$ value.

Once a DC/DC converter has been also included within the circuitry to be designed, further physical effects have to be taken into account in order to optimally designing the $\mathbf{V}_{\mathbf{b a t t}}$ value; for this reason, some other details on the "crucial" designing procedure of the $\mathbf{V}_{\text {batt }}$ value will be given on next section 3 in which DC/DC converters are also expressly involved. 


\section{Introducing a Boost-Type DC-DC Converter Acting as a "Second Order" Active MPPT}

In order to optimally control the actual value of voltage, $\mathbf{V}_{\mathbf{p v}}$, at the terminals of a generic sub-PV-string (or single PV-module), starting from the rated voltage value, $\mathbf{V}_{\text {batt }}$, of the battery pack introduced in section 2 , a boosttype DC-DC converter can be interposed between them, as depicted in Fig. 2. By this way the generation of the maximum available power of the sub-PV-string should be guaranteed under any solar irradiance level, any load/grid condition, for any value of the working temperature of its PV-cells and also for any $\mathbf{V}_{\text {batt }}$ value.

At a first sight, the aforementioned solution could appear the same used in conventional active MPPT; nevertheless, please note that in conventional active MPPTs a capacitor is utilized instead of a battery-pack. This means that, in conventional active MPPTs, a conspicuous energy-storage is not achievable; furthermore the capacitor cannot maintain the output voltage within a specified value and, in order to achieve the generation of the maximum power, the range of variations of the converter duty-cycle, $\mathrm{k}$, could result very large, so seriously affecting its conversion efficiency, because of significant conduction losses on its power switches.

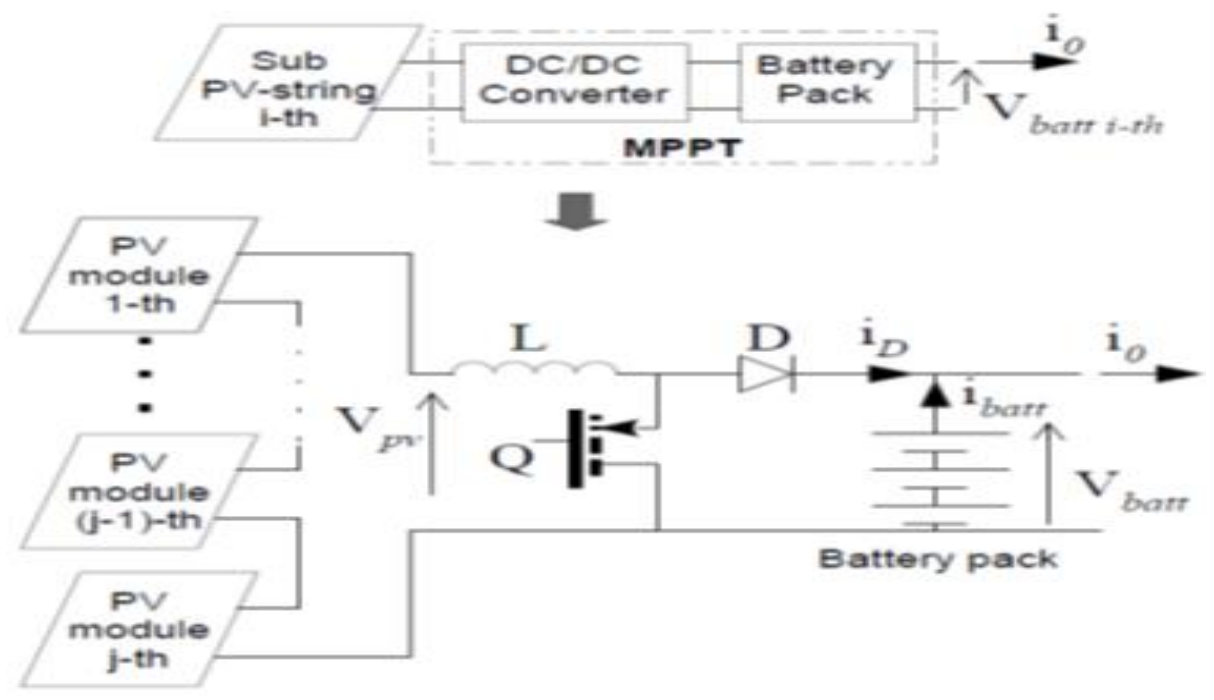

Fig-2. An MPPT based on a battery-pack connected to a sub-PV-string via a boost-type DC/DC converter

In order to obtain very reduced conduction (and conversion) losses, the boost-type DC/DC converter should be operated with very low values of its duty-cycle, $\mathrm{k}$, and this can be accomplished only if the $\mathbf{V}_{\text {batt }}$ value has been firstly optimized by taking into account not only the atmospheric conditions of the installation site together with the operating characteristics of the sub-PV-string but also intrinsic physical and operating characteristics of the boosttype DC/DC converter and its circuit components.

In fact, taking into account that the DC/DC converter is of the boost-type, on the one hand, the $\mathbf{V}_{\text {batt }}$ value should be chosen equal or higher than the theoretical $\mathbf{V}_{\mathbf{m p}}$ value of the sub-PV-string under the maximum estimated SI level and the lowest estimated Tc value; on the other hand, as specifically evidenced in the section dedicated to experiments, there are also other practical aspects that have to be taken into account in selecting the $\mathbf{V}_{\text {batt }}$ value. This is essentially because the DC/DC converter also introduces parasitic resistances (i.e. intrinsic resistances of circuit contacts, of the inductor, L, and of the diode, D) together with an almost constant voltage drop on the power diode, D. This means that, when the sub-PV-string generates power with the DC/DC converter switched-off (i.e. $\mathrm{k}=0$ ), the actual voltage, $\mathbf{V}_{\mathbf{p v}}$, at the terminals of the sub-PV-string is the sum of the $\mathbf{V}_{\mathbf{b a t t}}$ value and the whole voltage drops on DC/DC converter components; that is to say, $\mathbf{V}_{\text {pv }}$ can be also spontaneously higher than $\mathbf{V}_{\text {batt }}$.

This aspect could be not so evident and, if neglected, it could result in choosing a too high $\mathbf{V}_{\text {batt }}$ value; as a consequence, also in presence of batteries the DC/DC converter would be operated with too high $\mathrm{k}$ values so being affected by high conduction losses on the power switch, as in conventional active MPPTs simply using capacitors.

Unfortunately, this last aspect strongly depend from physical characteristics of the DC/DC converter circuitry (i.e. voltage, current and power rating of circuit components) and, as a consequence, the designing procedure of the $\mathbf{V}_{\text {batt }}$ value, far from being simply solvable by means of mathematical formulas, remains a very delicate practical issue.

In this sense, the use of a reliable and all inclusive numerical model of the circuitry under study can result of a great relevance, as well underlined in section 5 specifically dedicated to experiments.

Before to give (in section 5) some other practical insights on this specific aspect, in next section 4 the use of the proposed battery-based "hybrid" MPPT is extended to those grid-connected PV-plants in which mismatches among PV-modules of the same PV-field could cause important generation losses, also in presence of a single centralized MPPT. In fact, in our opinion, in this scenario the proposed use of batteries becomes affordable and achieves its maximum practical effectiveness.

Finally, about the hardware and the software that - of course - have to be used for automatically controlling the aforementioned DC/DC converters needed to continuously optimize the $\mathbf{V}_{\mathbf{p v}}$ value, please note that no differences occur with respect to what is already necessary to provide for DC/DC converters involved in conventional active MPPTs without batteries and any kind of the already well known MPPT algorithms can be implemented with no differences on the needed hardware and/or software. In this sense, also for the sake of brevity, further insights about will not be done in this paper without any loss of information. 


\section{Utilizing Batteries in a Distributed Framework}

As well known, manufacturing tolerances of PV-cells, different orientations of PV-modules, partial shadowing of PV-modules (caused by any kind of physical obstacle) and so on are causes of mismatching conditions among all the series-connected components of a PV-string, which generated current is limited to the lowest value generated by its "worse component".

Even if PV-modules endowed with "by-pass" diodes can simply alleviate the problem, the available power of the by-passed modules is completely lost; furthermore, the P-V characteristic of the PV-string under mismatches becomes "multi-modal" and - as well known - this could cause malfunction of the conventional centralized active MPPT systems together with significant losses on the generated power [16].

Distributed Maximum Power Point Tracking (DMPPT) systems have been introduced to overcome the aforementioned problems and to optimize the generation of PV-fields in presence of mismatching phenomena [1725] again, they are based on the use of DC/DC converters dedicated to each PV-module of a PV-string, in order to realize, in a decentralized manner, the MPPT for each PV-module; different kinds of useful DC/DC converters (mainly: boost, buck, buck-boost, cuck) can be used.

Undoubtedly, major problems related to DMPPTs are: additional costs, additional losses on DC/DC converters and reduced reliability of the resulting more complex circuitry. Nevertheless, an additional problem has been recently evidenced and investigated [24]; [25]. In practice, because of the series connection, at their output ports, of the distributed DC/DC converters of each PV-module, the voltage at the output terminals of a single DC/DC converter directly depends on the ratio between its generated power and the whole power generated by the PV-string. As a consequence, in case of mismatching conditions, the voltage at the output terminals of the DC/DC converter providing greater power can become very large so causing dangerous voltage stresses on its circuit components. To avoid destruction of converter components, a voltage limitation technique must be implemented or the MPPT function must be temporarily stopped, and this immediately causes relevant reductions on the whole generated power. In order to contain this kind of additional losses on the whole power generated by a PV-string endowed by a DMPPT, in Vitelli [25] Authors propose to add a central MPPT on the PV-string inverter, in order to optimally control the values of its input voltage (also, the whole output voltage of the PV-string). Nevertheless, an additional circuitry (and costs) is needed, without totally avoiding generating losses caused by mismatches.

In this last contest, as an alternative to conventional distributed and fully active MPPTs, our proposal is that of simply extending to this new distributed framework, the battery-based "hybrid" MPPT introduced in section 3; this new idea can be firstly appreciated with the help of Fig.3.

In practice, the PV-field is, firstly, partitioned into an appropriate number of PV-strings; then, for each PV-string, the PV-modules characterized by a very reduced probability of mismatches among them are identified and grouped in a certain number of sub-PV-strings (in the worst case, a sub-PV-string would coincide also with a single PVmodule); each sub-PV-string, together with its DC/DC converter and its battery-pack, constitutes - de facto - a single "battery-based DC-generator". Once all the sub-PV-strings characterized by an almost uniform exposition to atmospheric agents have been identified and all the battery-based generators have been planned, these last can be connected in series among them within the same PV-string, that is in turn conventionally connected to the grid by means of a central inverter.

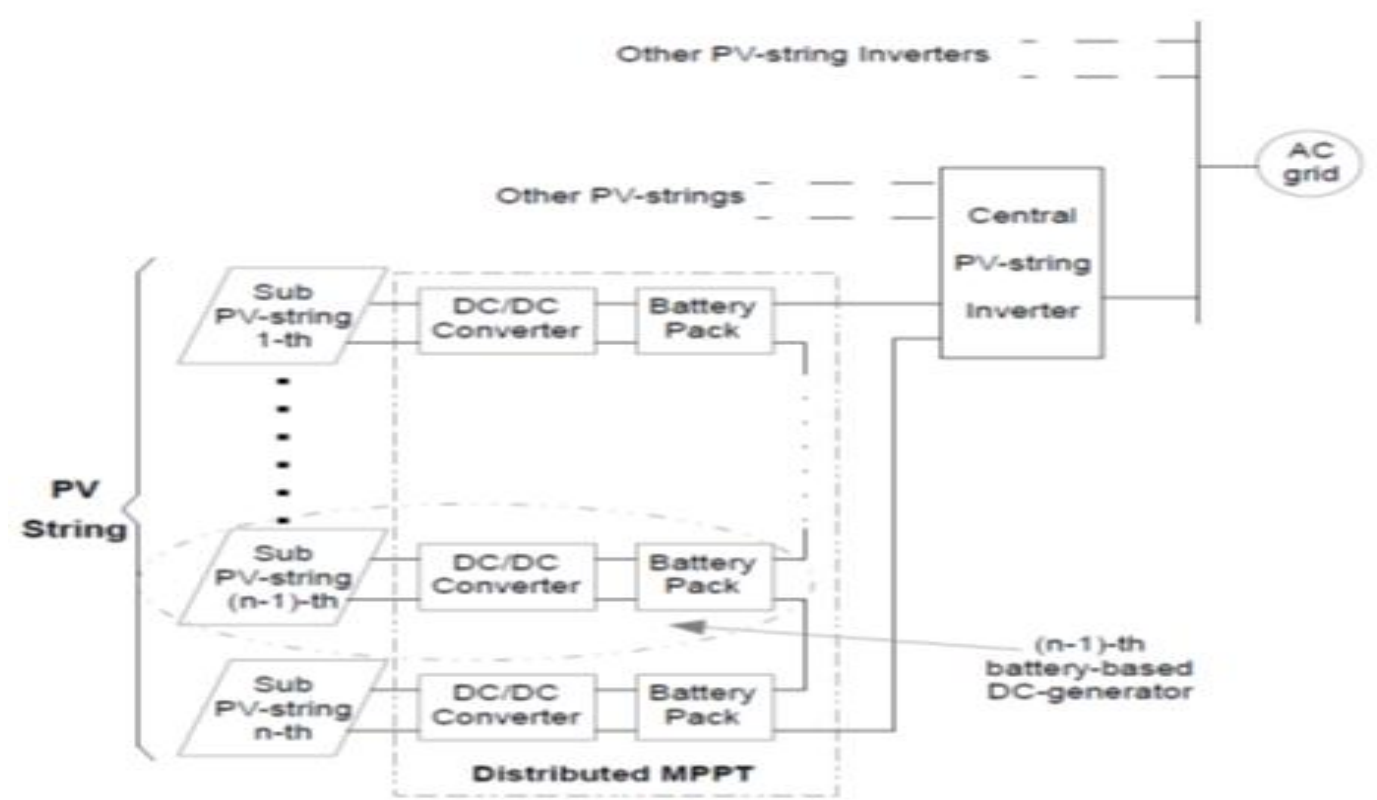

Fig-3. Architecture of a grid-connected PV-Plant with the proposed battery-based Distributed MPPT

The architecture depicted in Fig.3 has two fundamental novel properties.

The first one is that, even if all the battery-based DC-generators are connected in series at their output terminals, the corresponding DC/DC converters are not connected in series among them as in conventional DMPPTs. In fact (see also Fig.2), the output current of the PV-string, io, injected into the grid or given to the load and also common to all the battery-based DC-generators, is the sum of the DC-DC converter current, $\mathbf{i}_{\mathrm{D}}$ and the battery current, $\mathbf{i}_{\text {batt }}$; this means that, if one (or more) sub-PV-string is not irradiated as the other ones, thanks to its own battery-pack, its associated DC-generator can generate (temporarily and within limits of the capacity of the battery pack), the same current io generated by well-irradiated sub-PV-strings. In this way, each sub-PV-string can generate its own maximum available power (in virtue of the irradiance level and the temperature of the PV-cells), regardless of: the grid/load operating conditions, the ratio among the power generated by each sub-PV-string and the whole power 
generated by the PV-string, the value of the whole input inverter voltage and so on.

Its second fundamental property is that the whole output voltage of the PV-string, that is also the input voltage of the central inverter, is quite constant and fixed (at the designed stage) by a proper selection of the sub-PV-string battery packs; this guarantees both maximum efficiency for the inverter and no overvoltage stresses on the DC-DC converter components, regardless of possible mismatching conditions among the sub-PV-strings of the PV-field.

Please also note that different battery-packs on different sub-PV-strings are introduced to cope only with temporary (short-time) mismatches among sub-PV-strings (e.g. temporary partial shadowing). This means that, within limits of the capacity of batteries that have to be designed taking into account the mismatches to be coped with, the battery-pack of the worse irradiated sub-PV-string does not never undercharge and its voltage will remain of the same order of voltages at the terminal of other battery-packs in series. Furthermore, overcharge and undercharge of battery-packs can be simply managed by controlling the power flowing though the central inverter.

\section{Experiments}

Different experiments are now performed in order to prove the validity of our introduced battery based PVcircuits. The circuit with a single battery-based hybrid MPPT is fully analyzed in next sections 5.1 while a case-study referring to a more complex and realistic PV-plant with a distributed MPPT is analyzed in section 5.2.

\subsection{Experiments on a Single Battery-Based Hybrid MPPT}

On the basis of Fig. 2 a small power $(24 \mathrm{Wp}$ ) prototype has been developed in our lab and is now fully tested by means of both lab measurements and numerical simulations on the well known Pspice environment; An artificial light irradiation system based on $2 \times 500 \mathrm{~W}$ halogen projectors is also used to obtain different irradiation levels together with a small air fan properly operated for controlling the working temperature of the PV cells. The electrical scheme of the prototype together with most important parameter values are reported in Fig.4. It is a very low power prototype and it has been intended basically for properly setting an effective and all inclusive Pspice numerical model to be used for simulating and testing more complex circuitries including PV generators, DC/DC converters and batteries; nevertheless, here it is also used to prove, even if an "in an amplified way", some basic and important differences between the proposed battery-based circuit and conventional circuits based on capacitors.

The results of measurements on the lab prototype have been always compared with the results of respective numerical simulations performed by using the aforementioned all-inclusive Pspice numerical model, whose specific modeling characteristics have been already evidenced and analyzed in detail in Carbone, et al. [26].

About rated characteristics of batteries used on board of the lab prototype, please note that 6 commercial NiMH rechargeable batteries with $1.2 \mathrm{~V}$ of rated voltage and $2100 \mathrm{mAh}$ of capacity have been always used and different battery-packs have been made for experiments.

Firstly, a battery-pack with a $3.6 \mathrm{~V}$ rated voltage and $4100 \mathrm{mAh}$ of capacity (2 packs of 3 series-connected batteries in parallel) has been introduced within the circuitry of the lab prototype and, then, it has been fully tested under different operating conditions.

In Fig.5 the measured (left) and simulated (right) waveforms of the $\mathbf{Q}$ gating signal, $\mathbf{V}_{\text {pulse }}$, and of the current generated by the mini PV-module in a case-study operating condition, are reported for a first qualitative comparison between measurements and numerical simulations. In Fig. 6 and Table 1 some additional results, obtained under variable operating conditions, are also reported; a good matching between the Pspice numerical model and the lab prototype is always well evident. Furthermore, please note that the maximum available power is always generated by the battery-based PV-generator, under any load conditions and for any value of the working temperature of PV-cells.

In order to give also additional insights about most important differences between the proposed battery-based MPPT and the conventional MPPT using capacitors, some additional numerical experiments have been performed under critical grid/load operating conditions.

In particular, with reference to Fig. 4 a capacitor with $\mathrm{C}=470 \Omega \mathrm{F}$ has been introduced as an alternative to the battery-pack and operating conditions characterized by both a very high value $(20 \Omega)$ and a very low value $(0.2 \Omega)$ of the equivalent resistance of the grid (or of the load), $\mathbf{R}_{\text {load }}$, have been considered.

The circuit operation needed for the generation of the maximum available power, $\mathbf{P}_{\text {gmax }}$, has been found for both the battery-based MPPT and the conventional (or capacitor-based) MPPT, that is to say optimal values of the DC/DC converter duty-cycle, $\mathrm{k}$, have been identified (in our case, off-line and "manually") and then they have been imposed on different circuitries.

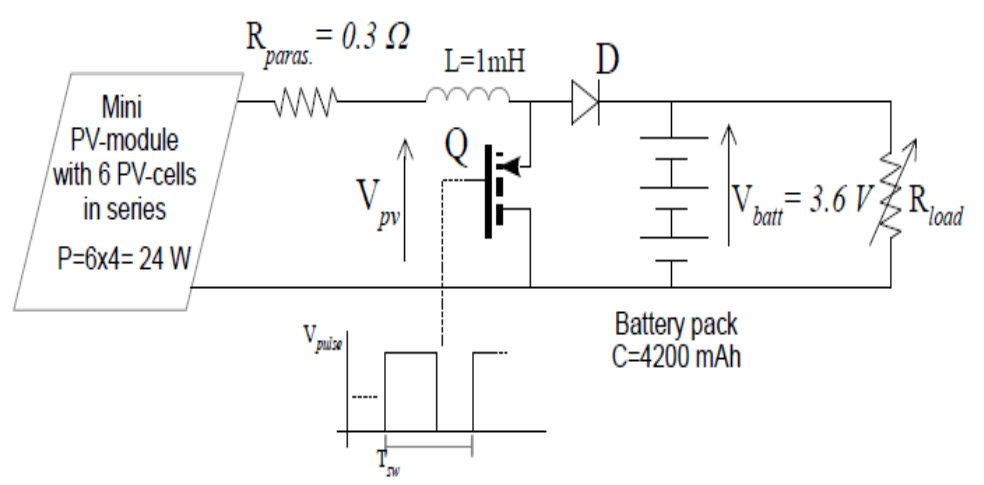

Fig-4. Electrical scheme of the small-power PV-generator prototype developed in the laboratory 


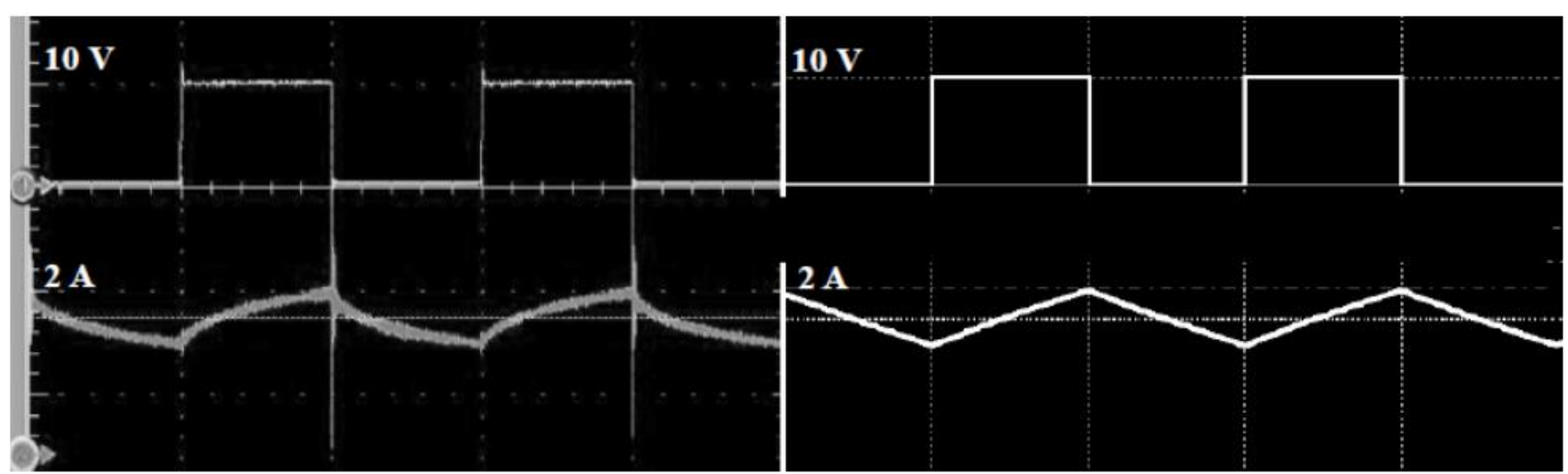

Fig-5. Measured (left) and simulated (right) waveforms of the $\mathbf{Q}$ gating signal and the current generated by the mini PV-module at: irradiance level $\mathbf{S I}=450 \mathrm{~W} / \mathrm{m}^{2}$, PV-cell temperature $\mathbf{T c}=45^{\circ} \mathrm{C}, \mathbf{f s w}=1 \mathrm{kHz}$, duty-cycle $=0.5$ and for a non-optimal load condition $(5 \Omega)$

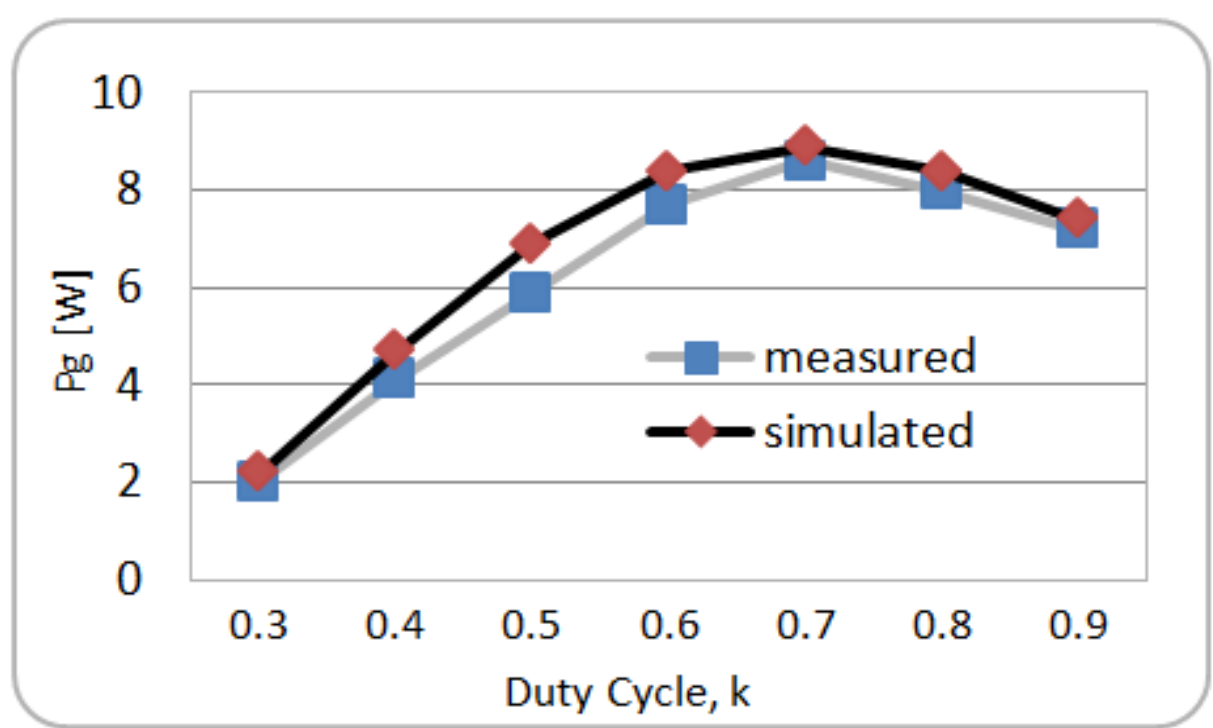

Fig-6. Power, $\mathbf{P g}$, generated by the lab PV module at the irradiance level $\mathbf{S I}=450 \mathrm{~W} / \mathrm{m}^{2}, \mathrm{PV}$ cell temperature $\mathbf{T} \mathrm{c}=25^{\circ} \mathrm{C}, \mathbf{f}_{\mathrm{sw}}=1 \mathrm{kHz}$ and for a non-optimal load condition $\left(\mathbf{R}_{\mathrm{L}}=5 \Omega\right)$, versus the value of the $\mathrm{DC} / \mathrm{DC}$ converter duty cycle, $\mathbf{k}$.

In the first case-study $\left(\mathbf{S I}=450 \mathrm{~W} / \mathrm{m}^{2}, \mathbf{T} \mathrm{c}=25{ }^{\circ} \mathrm{C}, \mathbf{R}_{\text {load }}=20 \Omega\right.$ ), the battery-based MPPT has simply achieved the generation of the maximum available power $(9 \mathrm{~W})$, with the same duty-cycle value utilized in the previous casestudies ( $\mathrm{k}=0.7$, as already indicated in Fig.6) and - as expected - maintaining at the terminal of the load a constant voltage of about $3.6 \mathrm{~V}$ (the rated voltage of the battery-pack). Instead, the capacitor-based MPPT has achieved the generation of the same maximum power but with a duty-cycle value significantly higher $(\mathrm{k}=0.87)$ and with a voltage at the terminal of the load of about $8.6 \mathrm{~V}$, that is to say more than two time higher than that of the battery-pack, so evidencing that in the conventional circuit the generation of the maximum available power could cause important overvoltages on circuitry components. Furthermore, starting from the $9 \mathrm{~W}$ generated power and unless most significant circuit power losses (about $5.3 \mathrm{~W}$ if evaluated as the summation of Joule losses on circuit parasitic resistances and the $\mathrm{Q}$ conduction losses) in the conventional circuit only $3.7 \mathrm{~W}$ have been delivered to the load and the circuit efficiency is found to be very low (about 40\%). In the proposed battery-based

Table-1. Measured and Pspice simulated values of the maximum power, $\mathbf{P}_{\text {gmax }}$, generated by the lab PV module, at the irradiance level $\mathbf{S I}=400 \mathrm{~W} / \mathrm{m}^{2}$, for different PV cell temperatures, $\mathbf{T}_{\mathrm{c}}$, under a non-optimal load, $\mathbf{R}_{\mathrm{L}}$, and at the optimal duty cycle, $\mathbf{k}_{\text {optimal }}$

\begin{tabular}{l|l|l|l|l}
\hline $\mathbf{R}_{\mathbf{L}}[\Omega]$ & $\mathbf{T}_{\mathbf{C}}\left[{ }^{\circ} \mathbf{C}\right]$ & $\mathbf{k}_{\text {optimal }}$ & $\mathbf{P}_{\mathbf{g m a x}}[\Omega]$ measured & $\mathbf{P}_{\mathbf{g m a x}}[\Omega]$ simulated \\
\hline \multirow{3}{*}{5} & 25 & 0.70 & 7.9 & 8.1 \\
\cline { 2 - 5 } & 45 & 0.73 & 7.6 & 7.8 \\
\cline { 2 - 5 } & 55 & 0.8 & 6.8 & 7.1 \\
\hline \multirow{3}{*}{3} & 25 & 0.70 & 7.9 & 8.2 \\
\cline { 2 - 5 } & 45 & 0.76 & 7.3 & 7.6 \\
\cline { 2 - 5 } & 55 & 0.78 & 6.6 & 7.2 \\
\hline
\end{tabular}

Circuitry, the generated power is not directly linked to the load condition thanks to the charging (or discharging) battery availability; furthermore, the DC-DC converter can be operated with a low and almost constant duty-cycle value (in this case $\mathrm{k}=0.7$ ), with reduced $\mathbf{Q}$ conduction losses and with a higher circuit efficiency of about $46 \%$. It is well evident that, with respect to commercial circuits, the circuit efficiency is anyhow very low also for the batterybased circuit, but this is mainly caused by both the high-value intrinsic parasitic resistances, $\mathbf{R}_{\text {paras. }}$, of the circuit (they have been experimentally estimated in about $0.3 \square$ and have been also included into the Pspice numerical model as indicated in Fig.4) and the very low rated power of our home-made prototype.

In the second case-study with very low load $\left(\mathbf{S I}=450 \mathrm{~W} / \mathrm{m}^{2}, \mathbf{T} c=25{ }^{\circ} \mathrm{C}, \mathbf{R}_{\text {load }}=0.2 \Omega\right)$, the battery-based MPPT has again achieved the generation of the maximum available power $(9 \mathrm{~W})$ with the same duty-cycle value, $\mathrm{k}=0.7$, and with no variation on the load voltage. Instead, the capacitor-based MPPT has achieved the maximum available power only with a zero value of $\mathrm{k}$ and with a very low value of the load voltage $(0.7 \mathrm{~V})$. For loads lower than $0.2 \square$, the battery-based MPPT has not any difficulty to always guarantee the generation of the maximum power; on the 
contrary, the capacitor-based MPPT is no longer able to guarantee the generation of the maximum power. In other words, the battery-based MPPT can easily cope with load variations while, on the contrary, the capacitor-based MPPT can cope only for limited variations of the load; furthermore, the conventional circuit produces a significant variation on the load voltage, also introducing (at very high-load values) the risk of pernicious overvoltages. This last relevant consideration will be re-analyzed with specific emphasis also in the next more complex case-study of a PVplant based on a conspicuous number of PV-modules and endowed with a "distributed" MPPT.

Even if advantages of the proposed battery-based circuit with respect to the conventional capacitor-based circuit are already well evident, it is very important to underline as performances of the proposed battery-based circuit can be further improved by better designing the rated voltage of the battery pack, $\mathbf{V}_{\text {batt, }}$ by taking into account information on the actual operating characteristics of the whole circuit under study that can be easily evidenced with the help of the Pspice numerical model. In fact, by using the first battery pack, not well designed because of its "too high" 3.6 V rated voltage, with the DC/DC converter switched-off (i.e. $\mathrm{k}=0$ ), the diode D results inversely biased for any load condition and the actual voltage at the terminal of the mini PV-module, $\mathbf{V}_{\mathbf{p v}}$, far from being close to the maximum power theoretical value of about $2.75 \mathrm{~V}$ (the $80 \%$ of the mini PV-module $\mathbf{V}_{\mathbf{o c}}$ ), practically approaches the $\mathbf{V}_{\mathbf{o c}}$ value (of about $3.6 \mathrm{~V}$ ) and no power is generated by the $\mathrm{PV}$-module. As a consequence, in order to generate the maximum available power the DC/DC converter has to be operated with a high value of $\mathrm{k}$ (i.e. $\mathrm{k}=0.7$ as already shown in Fig.6), so unsuitably working with high conversion losses.

Instead, a second battery pack with a lower $2.4 \mathrm{~V}$ rated voltage (3 packs of 2 series-connected batteries in parallel) is now used under the same atmospheric conditions $\left(\mathbf{S I}=450 \mathrm{~W} / \mathrm{m}^{2}\right.$ and $\left.\mathbf{T c}=25{ }^{\circ} \mathrm{C}\right)$. In this case, if the DC/DC converter is switched-off the diode D results forward biased; nevertheless, because the voltage at the terminal of the mini PV-module, $\mathbf{V}_{\mathbf{p v}}$, is clearly the summation of some significant voltage drops (i.e. those on circuit intrinsic and parasitic resistances, $\mathbf{R}_{\text {paras }}$, and on the diode, D) and the battery voltage, $\mathbf{V}_{\text {batt }}$, the $\mathbf{V}_{\mathbf{p v}}$ voltage again results too high with respect to the maximum power optimal value and it results instead very close to the $\mathbf{V}_{\text {oc }}$ value (in fact, it results of about $3.3 \mathrm{~V}$ ). This means that also by using a $2.4 \mathrm{~V}$ battery-pack, for generating the $9 \mathrm{~W}$ maximum available power of the case-study, the DC/DC converter has to be operated with a relatively high duty cycle value $(\mathrm{k}=0.6)$ and conversion losses are again high; anyway, a sensible improved circuit efficiency of about $51 \%$ has been registered.

In our specific case-study in which the lab prototype is characterized by components with a very small rated power (i.e the diode $\mathrm{D}$ alone introduces a "here sensible" voltage drop of about $0.6 \mathrm{~V}$ ), the use of a third battery pack with an apparently/theoretically "too low" $1.2 \mathrm{~V}$ rated voltage (6 batteries in parallel) has - instead - provided the best circuit performances also evidencing some additional and very interesting properties of using a battery-pack with an accurately designed rated voltage, chosen on the basis of an in depth investigation of the actual whole circuit operating characteristics. In fact, by using a $1.2 \mathrm{~V}$ battery-pack and by operating the circuitry with the DC/DC converter switched-off, the $\mathbf{V}_{\mathbf{p v}}$ voltage now spontaneously results of about $2.9 \mathrm{~V}$, that is to say it is intrinsically close to the optimal theoretical value of about $2.75 \mathrm{~V}$; as a consequence, in order to generate the $9 \mathrm{~W}$ maximum available power, now the DC/DC converter can be operated with very low values of $\mathrm{k}(\mathrm{k}=0.2)$ for any load condition and conduction losses on the power switch (and also conversion losses) are strongly reduced by reaching a circuit efficiency of about $60 \%$. In order to better appreciate this positive result, please note that the maximum efficiency of our home-made circuit under study can be obtained by using the conventional capacitor-based circuitry working under the optimal load with the DC/DC converter switched-off $(\mathrm{k}=0)$; in this (very rare) condition, a maximum efficiency of about $64 \%$ has been registered.

Further by investigating more in depth the use of the $1.2 \mathrm{~V}$ battery-pack other important aspects come out. As can be trivially evidenced, starting from the maximum available power, $\mathbf{P g}_{\max }$, generated by the PV-module, the really "helpful" power, that is to say also the "net power", $\mathbf{P}_{\text {net }}$, is the one that remains after Joule power losses on circuit parasitic resistances and also after conversion losses on the DC/DC converter; obviously, this last losses are null if $\mathbf{Q}$ is always switched-off (i.e. $\mathrm{k}=0$ ). That said, by using the $1.2 \mathrm{~V}$ battery-pack, if $\mathbf{Q}$ is switched-off a $\mathbf{V}_{\mathbf{p v}}$ voltage at the terminals of the PV-module of about $2.9 \mathrm{~V}$ is obtained, for any load and for any atmospheric condition. This voltage value, even if is not coincident with the maximum power voltage value, is close to it and is suitable for generating a non optimal but "congruous" power value under a lot of load and atmospheric conditions, also with the DC/DC converter switched-off (i.e. without conversion losses). Even, in most operating conditions, it could guarantee a $\mathbf{P}_{\text {net }}$ power higher than that obtained with the DC/DC converter switched-on for generating the maximum available power, $\mathbf{P g}_{\max }$.

As an example, please consider one of the last discussed case-study $\left(\mathbf{S I}=450 \mathrm{~W} / \mathrm{m}^{2}, \mathbf{T c}=25{ }^{\circ} \mathrm{C}, \mathbf{R}_{\text {load }}=20 \Omega\right)$. In this case, by operating the $1.2 \mathrm{~V}$ battery-based circuitry with the low $\mathrm{k}=0.2$ value of the converter duty-cycle, the maximum power $2.75 \mathrm{~V}$ voltage value for the $\mathbf{V}_{\mathbf{p v}}$ has been easily obtained and the generation of $9 \mathrm{~W}$ maximum available power has been registered together with the best $60 \%$ value for the circuit efficiency; this also means that, starting from the $9 \mathrm{~W}$ generated power, a net power of $5.4 \mathrm{~W}$ has been practically obtained. Now, if $\mathbf{Q}$ is simply switched-off, of course, the generation of the maximum power is lost; nevertheless, under the new $2.9 \mathrm{~V}$ non optimal value of $\mathbf{V}_{\mathbf{p v}}$ a non optimal power of $8.4 \mathrm{~W}$ is generated and, by avoiding additional losses on $\mathbf{Q}$, an improved $\mathbf{P}_{\text {net }}$ power of about $6 \mathrm{~W}$ is obtained.

Far from being a phenomenon to be relegated to a single and specific case-study, the aforementioned "smart" use of a battery-pack with a properly designed rated voltage together with a switched-off DC/DC converter can be extended to a wide set of operating conditions. In fact a detailed analysis of the circuitry behaviour has been performed by considering also variations on the load conditions, on the SI levels and also on the Tc temperature; the results are summarized with the help of Figs. from 7 to 11 .

Firstly, in Fig.7 the maximum power, $\mathbf{P g}_{\max }$, generated by different possible circuitries operating under variable SI levels, have been reported; specifically, powers generated by the battery-based circuit with the converter switched-off $\left(\mathbf{P}_{\text {batt }}\right)$, powers generated by the battery-based circuit with the converter switched-on $\left(\mathbf{P}_{\text {conv-batt }}\right)$ and 
powers generated by the capacitor-based circuit with the converter switched-on $\left(\mathbf{P}_{\text {conv-cap }}\right)$ have been evaluated for fixed values of the load resistance and of the temperature of PV-cells.

Fig.7 evidences as, by simply utilizing the $1.2 \mathrm{~V}$ battery-pack with the converter always switched-off, because of a non perfect uncontrolled value of the voltage, $\mathbf{V}_{\mathbf{p v}}$, at the terminals of the PV-module, the generated power is lower than the maximum power generated, with the converter switched-on, both by using the battery-pack or a conventional capacitor; the failure in the generation of the maximum available power is more evident at high values of the SI levels.

Please also note that, the battery-based circuit with the converter switched-on always generates the maximum

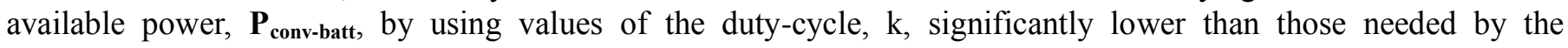
conventional capacitor-based circuit for guaranteeing the generation of the same maximum power, $\mathbf{P}_{\text {conv-cap}}$, especially a low SI levels.

Nevertheless, because of Joule power losses on parasitic circuit resistances and conversion losses on working converter, a greater generated power does not necessarily correspond to a greater useful net power, $\mathbf{P}_{\text {net }}$, delivered to the load or stored within the battery-pack (where it exists).

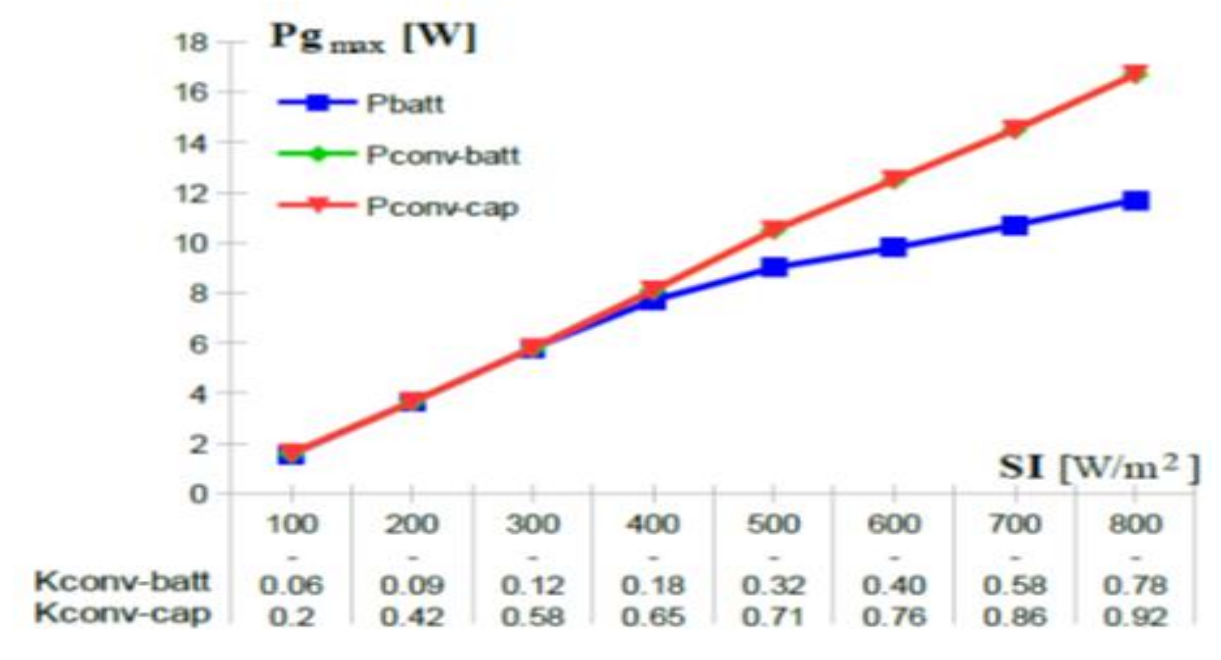

Fig-7. Maximum power, $\mathbf{P g}_{\max }$, generated by different circuitries under variable $\mathbf{S I}$ levels for:

$\mathbf{T c}=45^{\circ} \mathrm{C}$, fsw $=10 \mathrm{kHz}$ and a non-optimal load condition $\mathbf{R}_{\mathbf{l o a d}}=3 \Omega$.

Starting from this last consideration, maximum values of the aforementioned "net power", Pnet max $_{\text {, }}$ generated by our home made circuit under variable test conditions (different values of $\mathbf{S I}$, Tc and $\mathbf{R}_{\text {load }}$ ) are also evaluated for all the three different circuit configurations; the results are then compared and discussed with help of Figs.8-10.

Fig. 8 evidences that, under a variable load and constant values of SI and Tc, the maximum net power "caught" by the battery-based circuit with the converter switched-off is always greater than the power generated by other two "active" circuits (with respective converters switched-on). The conventional capacitor-based circuit is able to guarantee the maximum available net power only under optimal load conditions; on the contrary, under non optimal load conditions, the maximum available power is always generated (thanks to the help of the working converter) nevertheless the net generated power is "dramatically" low, because of both Joule and conversion higher power losses. On the battery-based circuit, by activating the converter, the maximum available power is now generated but this does not correspond to an increment of the net generated power that results always sensible lower than that guaranteed with the converter switched-off.

Very similar considerations can be also developed referring to variable SI and Te values (Figs. 9 and 10).

In practice, they confirm that, if the $\mathbf{V}_{\text {batt }}$ value is accurately designed basing on the analysis of actual circuit operating characteristics, active circuits that operate a converter for implementing an accurate maximum power tracking function do not certainly guarantee an advantage in generating a useful net power.

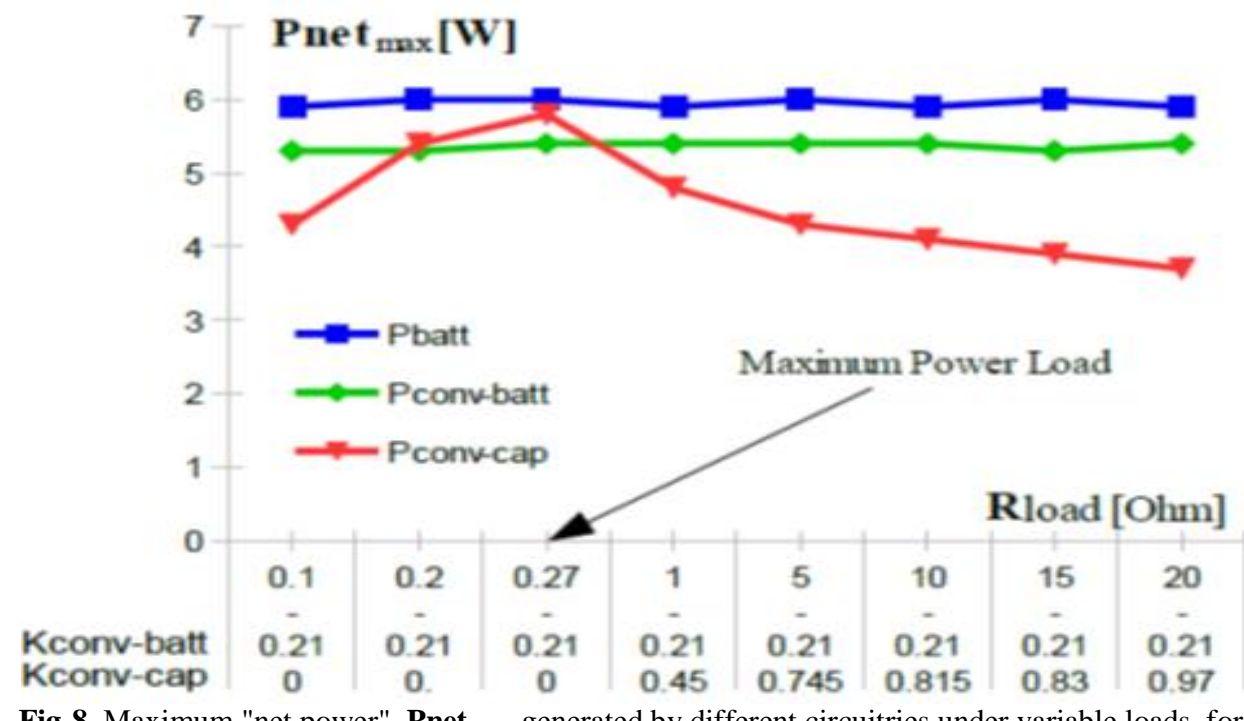

Fig-8. Maximum "net power", Pnet $_{\max }$, generated by different circuitries under variable loads, for: $\mathbf{T} \mathbf{c}=25^{\circ} \mathrm{C}, \mathbf{f s w}=10 \mathrm{kHz}$ and $\mathbf{S I}=450 \mathrm{~W} / \mathrm{m}^{2}$. 


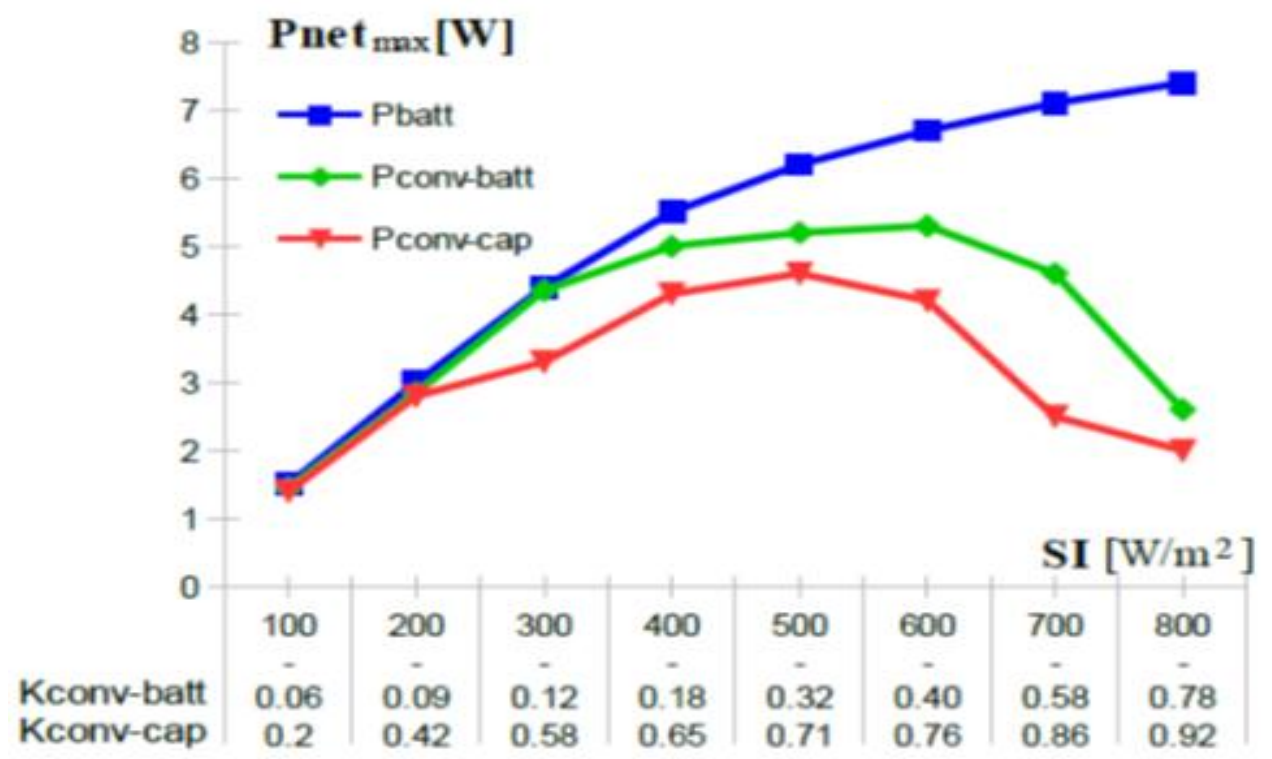

Fig-9. Maximum "net power", Pnet $_{\max }$, generated by different circuitries under variable SI, for: $\mathbf{T c}=25^{\circ} \mathrm{C}$, fsw $=10 \mathrm{kHz}$ and $\mathbf{R}_{\text {load }}=3 \Omega \Omega$

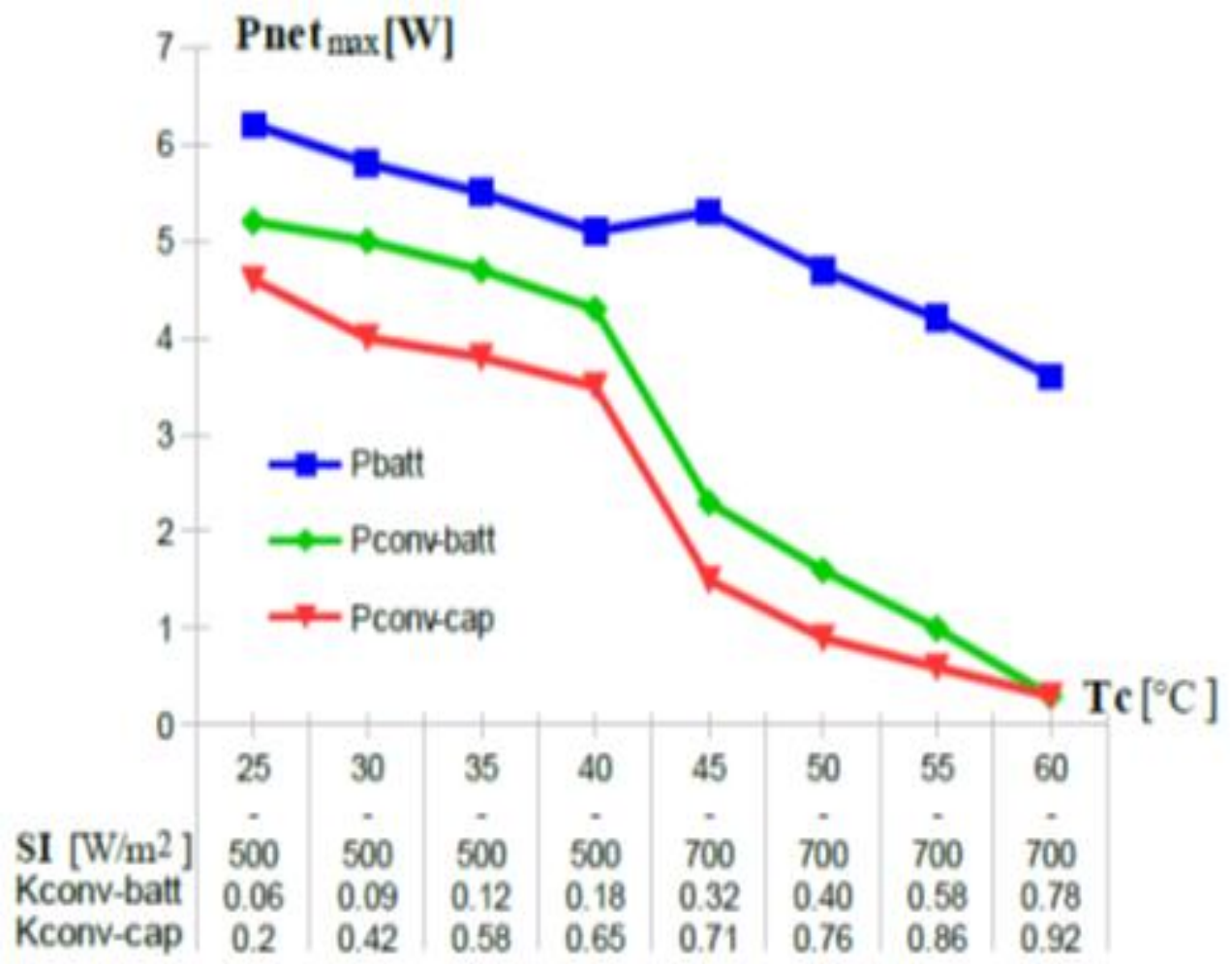

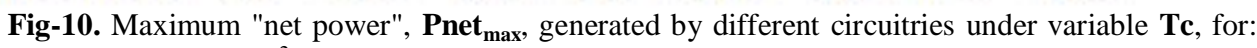
$\mathbf{S I}=500$ and $700 \mathrm{~W} / \mathrm{m}^{2}, \mathbf{f s w}=10 \mathrm{kHz}$ and $\mathbf{R}_{\text {load }}=3 \Omega \Omega$

Even, under certain atmospheric or load conditions, the activation of DC/DC converters for catching the generation of the maximum available power could be completely "frustrated" by the corresponding increment of Joule and conversion losses, resulting in the generation of a very low net power value. Of course, the aforementioned conclusion about the "ineffective" activation of DC/DC converters is strongly influenced by operating characteristics of our home-made prototype, specifically characterized by very low rated power and by a high value $(0.3 \Omega)$ of the whole circuit parasitic resistance, $\mathbf{R}_{\text {paras }}$; nevertheless, the aforementioned study is helpful for underlining that, within active MPPT circuitries based on DC/DC converters, by simply substituting capacitors with batteries, if the rated voltage of these last is accurately designed, the conversion efficiency can be improved by significantly reducing conduction losses on power switches.

Unfortunately, the study also confirms that the designing of the rated voltage of the battery-pack strongly depends on the actual intrinsic characteristics of the circuit components and a rigorous mathematical formalization in this sense is not possible; nevertheless, a preliminary use of a well-settled an all-inclusive numerical modeling of the circuitry could be very helpful for approaching an acceptable designing solution.

\subsection{Experiments on a PV-Plant Endowed with A DMPPT}

The previously settled Pspice numerical model is now used to give evidence of an additional relevant issue that can specifically affect PV-plants endowed with a conventional capacitor-based distributed MPPT. In fact, in this last case, a significant reduction of the generated power and/or possible destruction of circuit components can be caused also by circuit overvoltages that can appear in presence of strong mismatches among atmospheric exposition of different PV-modules of the same PV-string [23-25]. Also in this last context, the proposed battery-based circuitry with the architecture depicted in Fig.3 gives evidence of important and practical advantages with respect to conventional PV-plants without batteries. 
A typical residential PV-plant of about $1.5 \mathrm{kWp}$ is now investigated as a specific case-study; the PV-field is based on $6 \mathrm{PV}$-modules with $240 \mathrm{Wp}$ of rated power, under standard conditions $\left(1000 \mathrm{~W} / \mathrm{m}^{2}\right.$ of irradiance, SI, and 25 ${ }^{\circ} \mathrm{C}$ of temperature, Tc). Each PV-module is based on 60 series-connected PV-cells, each of one with about $4 \mathrm{Wp}$ of rated power, 8.17 of short-circuit current and $0.62 \mathrm{~V}$ of open-circuit voltage. For the sake of simplicity and without any loss of generality, only a single PV-string based on all the 6 series-connected PV-modules is hypothesized; this means that each PV-module is considered as a sub-PV-string and it is endowed with its proper boost-type DC/DCconverter MPPT (Fig.3).

In order to compare performances of the proposed battery-based architecture with those of a conventional one, the two respective different circuitries are simulated by means of the Pspice numerical model; without any loss of generality, the interfacing central inverter and the grid/load are modelled by an equivalent variable resistor, to simulate both optimal (central MPPT ON) and non optimal (central MPPT OFF) load/network operating conditions.

For the proposed battery-based architecture, taking into account the rated and operating characteristics of each PV-module under standard conditions, a lead acid valve-regulated battery pack with $24 \mathrm{~V}$ of rated voltage has been selected, in order to guarantee at the output terminals of each boost-type DC/DC converter a voltage value close to the respective PV-module maximum power voltage "standard" value (about 29 V); being our main objective that of compensating for possible momentary (some minutes) atmospheric severe mismatches among the PV-modules (e.g. momentary partial shadowing), a battery pack with a capacity value of $12 \mathrm{Ah}$ has been considered more than enough.

For the conventional capacitor-based architecture a $470 \Omega \mathrm{F}$ commercial aluminium electrolytic capacitor has been used, instead of the battery-packs.

Significant mismatches, in terms of different solar irradiance levels among the $6 \mathrm{PV}$-modules, are then considered; in particular, a $400 \mathrm{~W} / \mathrm{m}^{2}$ value for the irradiance level SI together with a $30{ }^{\circ} \mathrm{C}$ value of the Tc temperature are considered for first $5 \mathrm{PV}$-modules, while only for the sixth PV-module a $1000 \mathrm{~W} / \mathrm{m}^{2}$ SI value together a $60{ }^{\circ} \mathrm{C} \mathrm{Tc}$ value are hypothesized. Simulations have been carried out for evaluating the maximum power generated by each PV-module together with the total one generated by the whole PV-string, $\mathbf{P}_{\mathrm{g}}$, for different values of $\mathbf{R}_{\text {load. }}$. The whole net power, $\mathbf{P}_{\text {net }}$, generated by both PV-strings are also evaluated to take into account effects of different circuit additional power losses. The results are summarized with the help of Fig.11.

Also in this case the proposed architecture is able to generate the maximum available power of about $540 \mathrm{~W}$ (Fig.11) for any grid/load operating condition.

On the contrary, the conventional architecture seems able the generate the maximum power only starting from certain high values of $\mathbf{R}_{\text {load }}$; below a certain value of $\mathbf{R}_{\text {load }}$ (i.e. $50 \Omega$ in Fig.11), power generated by the less irradiated sub-PV-strings becomes null (in fact, their output voltage becomes null) and a loss of generated power is well evident. This means that, for the conventional architecture a central inverter is strictly needed for allowing the generation of the maximum available power by controlling the equivalent resistance value $\mathbf{R}_{\text {load }}$ [25] nevertheless, an additional problem arises.

In Fig. 12 the values of the PV-strings output voltage, $\mathbf{V}_{0}$, are reported together with the output voltage values, $\mathbf{V}_{0,6-\text { th }}$, at the terminals of the best irradiated sixth PV-module. From this last figure it is evident that, even if the $\mathbf{R}_{\text {load }}$ value is adjusted to be above the aforementioned $50 \Omega$ minimum value, in order to make

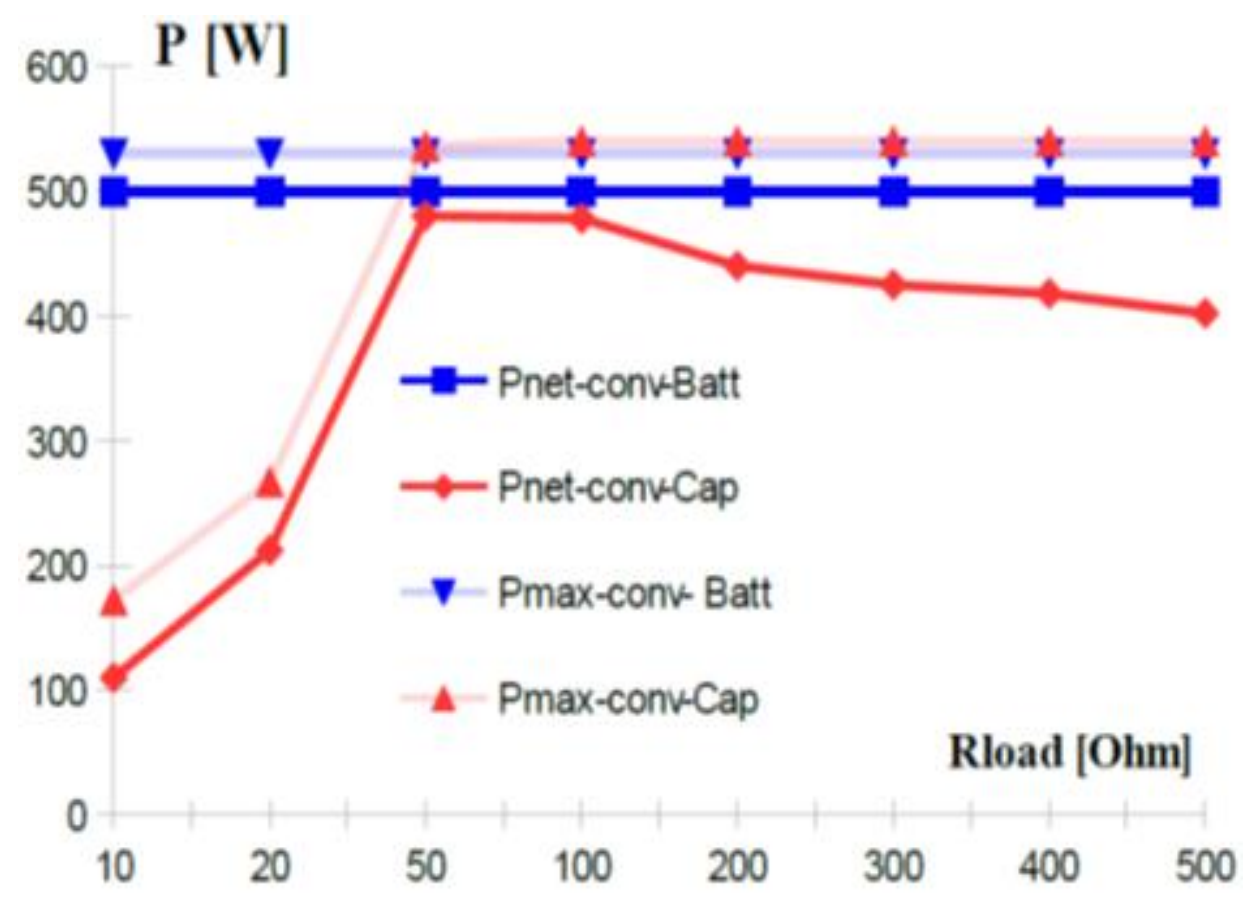

Fig-11. Maximum power, $\mathbf{P}_{\max }$, and net power, $\mathbf{P}_{\text {net }}$, generated by the 6 series-connected PVmodules case-study, at $\mathbf{f s w}=10 \mathrm{kHz}, \mathbf{T c}=25{ }^{\circ} \mathrm{C}$ and $\mathbf{S I}=400 \mathrm{~W} / \mathrm{m}^{2}$ for $\mathrm{PV}$-modules from 1 to 5 and $\mathbf{T} \mathrm{c}=60{ }^{\circ} \mathrm{C}$ and $\mathbf{S I}=1000 \mathrm{~W} / \mathrm{m}^{2}$ for the 6th $\mathrm{PV}$-module, under non-optimal and variable grid/network equivalent resistance values, as registered in the conventional capacitor-based circuitry ("conv-Cap" subscript) and in the proposed battery-based circuitry ("conv-Batt" subscript). 


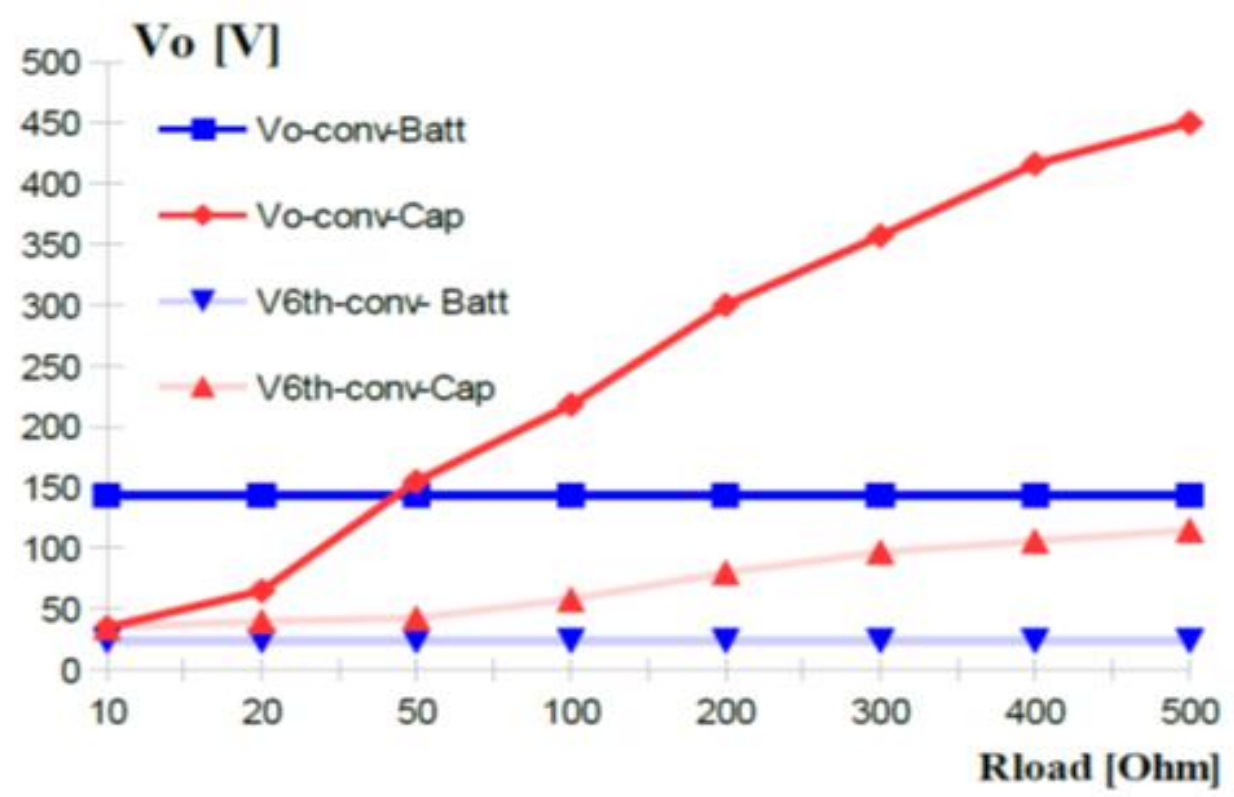

Fig-12. Whole output voltages, $\mathbf{V}_{0}$, and voltage at the output terminals of the 6th PV-module, $\mathbf{V}_{\text {6th }}$, of the 6 series-connected PV-modules case-study, under the operating conditions specified in Fig. 12, registered in the conventional capacitor-based circuitry ("conv-Cap" subscript) and in the proposed battery-based circuitry ("conv-Batt" subscript).

Possible the generation of the maximum available power, important overvoltages now appear within the conventional circuitry, especially at the terminals of the better irradiated sub-PV-string; as a consequence, for avoiding the destruction of some sensible circuit components, a "neutralizing" limitation logic of the generated power should be operated.

\section{Conclusion}

Batteries with accurately designed rated voltages have been introduced within grid-connected PV-plants to be used together with simple boost-type DC/DC converters. The proposal is mainly intended for complex PV-plants already endowed with a battery-based energy storage system and with a distributed MMPTs. By the proposed way, a high efficiency of the PV-generator is always guaranteed, also in presence of important criticalities in the PV-field and/or in the grid operating conditions. Differently from conventional PV-plant architectures with a conventional centralized battery-pack, the PV-plant generation can be optimized also in presence of strong partial shadings. Differently from conventional distributed MPPTs without batteries, a central MPPT function proved not to be strictly necessary for always generating the maximum available power and/or for avoiding dangerous overvoltages on circuit components. Further, all the well known advantages of the energy storage availability are de facto embedded within the PV-plant. Measurements on a lab prototype and Pspice numerical simulations have demonstrated the effectiveness of the proposed idea.

\section{References}

[1] R. Carbone, "Grid-connected photovoltaic systems with energy storage," presented at the IEEE International Conference on Clean Electrical Power, 2009. Capri - Italy, 2009.

[2] R. Carbone, "A passive MPPT technique for grid-connected photovoltaic systems," presented at the 20th International Conference and Exhibition on Electricity Distribution - Part 1. CIRED, 2009.

[3] C. S. Edrington, S. Balathandayuthapani, and C. Jianwu, "Analysis of integrated storage and grid interfaced photovoltaic system via nine-switch three-level inverter," presented at the IEEE Industrial Electronics Society Annual Conference IECON 2010 - 36th, 2010.

[4] R. Carbone, "Energy storage in grid-connected photovoltaic plants. INTECH Open Access Publisher, Chapter 4 of the Book EnergyStorage, Edited by Rafiqul Islam Sheikh." Retrieved from http://www.intechopen.com/books/energy-storage, 2010.

[5] S. Kai, Z. Li, Y. Xing., and J. M. Guerrero, "A distributed control strategy based on dc bus signaling for modular photovoltaic generation systems with battery energy storage," IEEE Transactions on Power Electronics, vol. 26, pp. 3032-3045, 2011. View at Google Scholar | View at Publisher

[6] D. Yang and D.-C. L. Dylan, "Battery-integrated boost converter utilizing distributed MPPT configuration for photovoltaic systems," Elsevier Solar Energy, vol. 85, pp. 1992-2002, 2011. View at Google Scholar | View at Publisher

[7] Energy Storage, "Energy storage in the emerging era of smart-grids. Edited by Rosario Carbone. Published by inTech. First published." Retrieved from www.intechopen.com. [Accessed September, 2011], n.d.

[8] C. Bong-Yeon, N. Yong-Su, J. Young-Hyok, L. Byoung-Kuk, and W. Chung-Yuen, "Battery-integrated power optimizer for PV battery hybrid power generation system," presented at the IEEE Vehicle Power and Propulsion Conference, Oct. 9-12, 2012, Seoul, Korea, 2012.

[9] S. M. Ali, P. Punyashree, S. Prasun, and R. R. Sabat, "Modeling and control of grid-connected hybrid photovoltaic distributed generation system," International Journal of Engineering Sciences \& Emerging Technologies, vol. 4, pp. 125-132, 2012. View at Google Scholar

[10] A. Burgio, R. Carbone, R. Morello, and A. Pinnarelli, "Grid-connected PV plants based on a distributed energy-storage system and a multilevel inverter," International Review of Electrical Engineering, vol. 8, pp. 1267-1278, 2013. View at Google Scholar

[11] K. Hongrae, B. Parkhideh, T. D. Bongers, and G. Heng, "Reconfigurable solar converter: A single-stage power conversion PV battery system," IEEE Transactions on Power Electronics, vol. 28, pp. 3788-3797, 2013. View at Google Scholar | View at Publisher

[12] N. Jabalameli, M. A. S. Masoum, F. Shahnia, and T. H. Mehr, "Impact of battery rating on performance of rooftop PV supporting household loads, regulating PCC voltage and providing constant output power to grid," presented at the Power Engineering Conference (AUPEC), 2013 Australasian Universities, 2013.

[13] H. Beltran, E. Bilbao, E. Belenguer, I. Etxeberria-Otadui, and P. Rodriguez, "Evaluation of storage energy requirements for constant production in PV power plants," IEEE Transactions on Industrial Electronics, vol. 60, pp. 1225-1234, 2013. View at Google Scholar $\mid$ View at Publisher

[14] S. Teleke, M. E. Baran, and S. Bhattacharya, Validation of battery energy storage control for wind farm dispatching. Proceedings of the 2010 IEEE Power and Energy Society general meeting, Minneapolis, MN, USA, 2010. 
[15] D. Nicholas, D. Aron, and J. Steven, "Economic analysis case studies of battery energy storage with SAM," Technical Report NREL/TP-6A20-649872015.

[16] T. Shimizu, O. Hashimoto, and G. Kimura, "A novel high-performance utility-interactive photovoltaic inverter system," IEEE Transactions on Power Electronics, vol. 18, pp. 704-711, 2003. View at Google Scholar $\mid$ View at Publisher

[17] G. Walker and P. Sernia, "Cascaded dc-dc converter connection of photovoltaic modules," IEEE Transactions on Power Electronics, vol. 19, pp. 1130-1139, 2004. View at Google Scholar $\mid$ View at Publisher

[18] H. Patel and V. Agarwal, "Maximum power point tracking scheme for PV systems operating under partially shaded conditions," IEEE Transactions on Industrial Electronics, vol. 55, pp. 1689-1698, 2008. View at Google Scholar $\mid$ View at Publisher

[19] N. Femia, G. Lisi, G. Petrone, G. Spagnuolo, and M. Vitelli, "Distributed maximum power point tracking of photovoltaic arrays: Novel approach and system analysis," IEEE Transactions on Industrial Electronics, vol. 55, pp. 2610-2621, 2008. View at Google Scholar $\mid$ View at Publisher

[20] C. Deline, B. Marion, J. Granata, and S. Gonzalez, "A performance and economic analysis of distributed power electronics in photovoltaic systems," Technical Report NREL/TP-5200-50003, 2011.

[21] S. Poshtkouhi, V. Palaniappan, M. Fard, and O. Trescases, "A general approach for quantifying the benefit of distributed power electronics for fine grained MPPT in photovoltaic applications using 3D modeling," IEEE Transactions on Power Electronics, vol. 27, pp. 4656-4666, 2011.

[22] S. Doron and L. Yoash, "Distributed maximum power point tracking in photovoltaic systems - emerging architectures and control methods," Automatika, vol. 53, pp. 142-155, 2012. View at Google Scholar | View at Publisher

[23] R. Alonso, E. Roman, A. Sanz, V. E. M. Santos, and P. Ibanez, "Analysis of inverter-voltage influence on distributed MPPT architecture performance," IEEE Transactions on Industrial Electronics, vol. 59, pp. 3900-3907, 2012. View at Google Scholar $\mid$ View at Publisher

[24] C. A. Ramos-Paja, A. J. Saavedra-Montes, and M. Vitelli, "Distributed maximum power point tracking with overvoltage protection for PV systems," Dyna, vol. 80, pp. 141-150, 2013. View at Google Scholar

[25] M. Vitelli, "On the necessity of joint adoption of both distributed maximum power point tracking and central maximum power point tracking in PV systems," Progress in Photovoltaics: Research and Applications, vol. 22, pp. 283-299, 2014. View at Google Scholar | View at Publisher

[26] R. Carbone, R. Carotenuto, C. F. G. Della, C. Felini, D. Lero, M. Merenda, and G. Pangallo, "SPICE modelling of a complete photovoltaic system including modules, energy storage elements and a multilevel inverter," Solar Energy, vol. 107, pp. 338-350, 2014. View at Google Scholar $\mid$ View at Publisher 